\title{
Copper deposition on TiO2 from copper(II)hexafluoroacetylacetonate
}

Article

Published Version

Rayner, D. G., Mulley, J. S. and Bennett, R. A. (2013) Copper deposition on $\mathrm{TiO} 2$ from copper(II)hexafluoroacetylacetonate. Journal of Vacuum Science and Technology A, 31 (1). $01 \mathrm{~A} 121$. ISSN 1520-8559 doi: https://doi.org/10.1116/1.4765644 Available at https://centaur.reading.ac.uk/29769/

It is advisable to refer to the publisher's version if you intend to cite from the work. See Guidance on citing.

To link to this article DOI: http://dx.doi.org/10.1116/1.4765644

Publisher: American Vacuum Society

All outputs in CentAUR are protected by Intellectual Property Rights law, including copyright law. Copyright and IPR is retained by the creators or other copyright holders. Terms and conditions for use of this material are defined in the End User Agreement.

\section{www.reading.ac.uk/centaur}

\section{CentAUR}

Central Archive at the University of Reading

Reading's research outputs online 


\title{
Copper deposition on $\mathrm{TiO}_{2}$ from copper(II)hexafluoroacetylacetonate
}

\author{
David G. Rayner, James S. Mulley, and Roger A. Bennett ${ }^{\text {a) }}$ \\ Department of Chemistry, University of Reading, Reading RG66AD, United Kingdom
}

(Received 2 August 2012; accepted 19 October 2012; published 7 November 2012)

\begin{abstract}
The authors have studied the adsorption of $\mathrm{Cu}^{\mathrm{II}}(\mathrm{hfac})_{2}$ on the surface of a model oxide system, $\mathrm{TiO}_{2}(110)$, and probed the molecular stability with respect to thermal cycling, using atomic scale imaging by scanning tunneling microscopy supported by x-ray photoemission spectroscopy. They find that at $473 \mathrm{~K}$, the adsorbed metal-organic molecules begin to dissociate and release $\mathrm{Cu}$ atoms which aggregate and form $\mathrm{Cu}$ nanoparticles. These $\mathrm{Cu}$ nanoparticles ripen over time and the size (height) distribution develops into a bimodal distribution. Unlike other organometallic systems, which show a bimodal distribution due to enhanced nucleation or growth at surface step edges, the nanoparticles do not preferentially form at steps. The reduced mobility of the $\mathrm{Cu}$ islands may be related to the co-adsorbed ligands that remain in very small clusters on the surface. (C) 2013 American Vacuum Society. [http://dx.doi.org/10.1116/1.4765644]
\end{abstract}

\section{INTRODUCTION}

Organometallic molecules are the key precursors employed in a wide range of technologies to deposit metallic and conducting structures on a wide range of materials with potential applications in molecular electronics, biosensors, and photocatalysis. Understanding and designing the properties of the molecule-substrate and molecule-molecule interactions is crucial to making improvements in technology. This is especially true in atomic layer deposition (ALD). In ALD monolayer metal organic molecular adsorbates are sequentially reacted to coat surfaces of inorganic materials with exceptional conformity and uniformity at near atomic layer precision. ${ }^{1}$ The method requires the formation of stable adsorbed species to block surface sites from further adsorption. This self-limiting adsorption behavior allows for a subsequent surface reaction to occur with a different gas phase species to deposit material on the surface as an oxide, metal, nitride, or sulfide. This material should be terminated in such a manner as to allow subsequent adsorption of a further cycle of organometallic molecules and their reactants leading to the perfect layer by layer construction of a desired material with atomic precision. Thermal decomposition of the metal organic precursor on the surface is a hindrance as control of the deposition process is compromised, the system may no longer be self-limiting and precision is probably lost. The deposition of elemental metals by ALD is inherently very difficult as on most oxide surface, there is a lack of suitable binding sites for the precursor molecules leading to long and unpredictable induction times, and once growth is started, there is a tendency for the metal to cluster and for nanoparticles to form.

$\mathrm{Cu}$ ALD is especially demanding as the relatively high surface energy of $\mathrm{Cu}$ and its weak interaction with many oxidic substrates leads to three-dimensional growth driven by thermodynamics. However, even at $160 \mathrm{~K} \mathrm{Cu}$ adatoms deposited by physical vapor deposition are mobile and threedimensional crystallites form on $\mathrm{TiO}_{2} \cdot{ }^{2}$ Hence, many low temperature processes are of interest both to maintain the integrity of the technological substrate and to limit $\mathrm{Cu}$

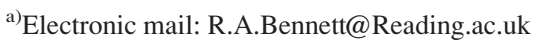

mobility and its tendency to form large sparse islanded arrays. In order to reduce the $\mathrm{Cu}$ ALD film roughness Co has been employed as a conformal seed layer to promote $\mathrm{Cu}$ nucleation and thus create smooth films on a variety of insulating substrates. ${ }^{1}$ More recently, Cu ALD at low temperature has been achieved by employing a ligand exchange mechanism ${ }^{3}$ although this suffers from incorporation of $\mathrm{Zn}$ from the reductant. Using a three step process, Winter has developed a low temperature ALD in which the precursor exchanges $\mathrm{Cu}$ with formic acid to create adsorbed $\mathrm{Cu}^{\text {II }}$ formate which is readily reduced to $\mathrm{Cu}$ metal by hydrazine. ${ }^{4}$

Our methodology is to look at the fundamental steps in ALD and probe the molecular properties and decomposition using well defined model systems. We carefully choose materials systems where we have good control and can maintain atomically clean surfaces through surface science techniques. For this study, we chose to investigate the adsorption of copper(II)hexafluoroacetylacetonate $\left(\mathrm{Cu}^{\mathrm{II}}(\mathrm{h}-\right.$ fac) $)_{2}$ ) which has been used as an precursor in the ALD of $\mathrm{Cu}^{5}{ }^{5}$ In previous work, ${ }^{6}$ we have used x-ray and UV photoemission spectroscopies (XPS and UPS, respectively) to characterize the molecular adsorption of $\mathrm{Cu}^{\mathrm{II}}(\mathrm{hfac})_{2}$ on titanium dioxide. The adsorption geometry of two adsorbed species was inferred from near edge x-ray adsorption fine structure (NEXAFS) experiments. These two species are composed of the hfac ligand and an hfac ligand bound to a $\mathrm{Cu}$ atom $\left(\mathrm{Cu}^{\mathrm{I}}\right.$ hfac $)$ and derive from the dissociation of the parent molecule. Both fragments bond to the surface, the hfac ligand binds through the two oxygen termini on to neighboring fivefold coordinated Ti ions in the (110) surface and the $\mathrm{Cu}^{\mathrm{I}}$ hfac through adsorption of the $\mathrm{Cu}$ on neighboring bridging oxygens in a square planar geometry. These molecular adsorbates block all adsorption sites and hence the adsorption is self-limiting at room temperature.

In this work, we characterize the deposition on the surface of $\mathrm{TiO}_{2}(110)$ of $\mathrm{Cu}$ nanoparticles from $\mathrm{Cu}^{\mathrm{II}}(\mathrm{hfac})_{2}$ and correlate the structures and key temperatures to our photoemission spectroscopies. For the work presented here, we show data obtained from the cross-linked $(1 \times 2)$ reconstructed surface which is a stable reconstruction obtained after bulk reduction of the crystal. ${ }^{7}$ The reconstruction is composed of 
added rows of $\mathrm{TiO}_{2}$ that are periodically cross-linked every 10-12 lattice spacings along the $\langle 001\rangle$ direction. The reconstruction can locally be lifted by reoxidation through exposure of oxygen to the surface at elevated temperature which allows the capture of thermally diffusing Ti interstitials and regrowth of $\mathrm{TiO}_{2}$ at the surface. ${ }^{8-11}$ The cross-links of the surface structure can be used to template the growth of metal nanoparticles. ${ }^{12}$ Both the bulk terminated $(1 \times 1)$ and crosslinked $(1 \times 2) \mathrm{TiO}_{2}(110)$ surfaces expose the fivefold coordinated $\mathrm{Ti}$ sites where hfac adsorbs and the bridging oxygen rows where $\mathrm{Cu}$ hfac adsorbs.

\section{EXPERIMENT}

The imaging experiments were performed in a WA Technology variable temperature scanning tunneling microscope (STM) system. The ultrahigh vacuum chamber is described in detail ${ }^{13}$ and since then has had the molecular beam removed. STM tips were formed from electrochemically etched $\mathrm{W} 95 \% / \mathrm{Re} 5 \%$ alloy wire. Images were quantitatively analyzed using custom software to determine particle sizes as shown previously. ${ }^{6}$ Briefly, the particle heights are measured from the maximum height of the particle to the mean height of the terrace at the periphery of the cluster (particles at step edges will have heights averaged over each terrace while those at the edges of the image are discarded). Images were also processed using the wsXm software. ${ }^{14} \mathrm{TiO}_{2}(110)$ single crystals (PIKEM, UK) were prepared by sequences of $\mathrm{Ar}^{+}$sputtering, vacuum annealing, and roasting in oxygen until well ordered low energy electron diffraction (LEED) patterns were obtained. $\mathrm{Cu}^{\mathrm{II}}(\mathrm{hfac})_{2}$ (Sigma Aldrich) was deposited onto the substrate by means of a dosing tube connected to a fine leak valve. The precursor was first dehydrated by extended pumping and changed color from green to grey (as earlier studies have employed ${ }^{15}$ ). During deposition, the substrate was at ambient temperature $(\sim 300 \mathrm{~K})$ and the metal organic precursor leaked into the chamber in a background pressure of $\sim 1 \times 10^{-5}$ Torr for $10 \mathrm{~min}$. This corresponds to exposing the surface to approximately $6000 \mathrm{~mol}-$ ecules per surface site $\left(\sim 5 \times 10^{-6} \mathrm{Mol} \mathrm{cm}^{-2}\right)$ and hence is a large excess. The dosed crystal was annealed for $5 \mathrm{~min}$ at increasing temperatures in $100 \mathrm{~K}$ increments and then imaged by STM at $300 \mathrm{~K}$. LEED patterns of the adsorbed system were not acquired due to the electron stimulated decomposition of the precursor. The experimental setup under which the photoelectron spectroscopy was performed are described previously. ${ }^{6}$

\section{RESULTS AND DISCUSSION}

\section{A. Room temperature molecular adsorption}

The clean reconstructed $\mathrm{TiO}_{2}(110)$ surface exhibits large flat terraces prior to deposition [Fig. 1(a)] in which there are a few pits within a terrace and step edges between terraces of single atomic step height ( $3.25 \AA$ ). The Fig. 1(b) shows the reconstruction more clearly as added rows running in the $\langle 001\rangle$ direction periodically linked every $8-12$ lattice spacings in this direction. Pits on the terrace lead to areas of the $(1 \times 1)$ terminated bulk surface upon which the $(1 \times 2)$ reconstruction has grown. Typically some clusters of contaminants are seen in the images $\left(\sim 1\right.$ per $\left.100 \mathrm{~nm}^{2}\right)$ as large apparent height particles of between 5 and $10 \AA$. Upon adsorption of $\mathrm{Cu}^{\mathrm{II}}(\mathrm{hfac})_{2}$ at room temperature (RT, $\sim 300 \mathrm{~K}$ ), the step edges, terrace, and pit morphology remains but the fine structure of the reconstruction is obscured, Fig. 1(c). The terraces display a speckled disordered structure with a perceptible striping along the $\langle 001\rangle$ rows. The change is characteristic of the adsorption of a molecular species on the surface. There is, however, a lack of any long range order which makes the images appear noisy. In comparison on the $(1 \times 1)$ terraces, a $(2 \times 1)$ molecular overlayer structure is observed by LEED indicative of long range order. If the adsorption of $\mathrm{Cu}^{\mathrm{II}}(\mathrm{hfac})_{2}$ on this crosslinked $(1 \times 2)$ surface behaves in the same way as on the bulk terminated $(1 \times 1)$, we expect two adsorbates to dominate-the hfac ligand adsorbed on fivefold coordinated $\mathrm{Ti}$ sites and $\mathrm{Cu}^{\mathrm{I}}$ hfac on bridging oxygen rows. Both of these adsorbates are bulky and bind bidentate to two surface ions in the substrate and so we expect a saturation coverage of a total of $\sim$ two bound species per $(1 \times 2)$ surface cell comprised of either one hfac ligand and one $\mathrm{Cu}^{\mathrm{I}} \mathrm{hfac}$ or two hfac ligands and a deposited $\mathrm{Cu}$ atom. Thus, the saturated $\mathrm{Cu}$ concentration of this adsorbate layer is expected to be around $2.5 \times 10^{14} \mathrm{~cm}^{-2}$. The as deposited images clearly show substrate step structure and the row structure of the reconstructed surfaces and hence strongly suggest that, despite the very large excess of molecules that the surface was exposed to, the adsorption

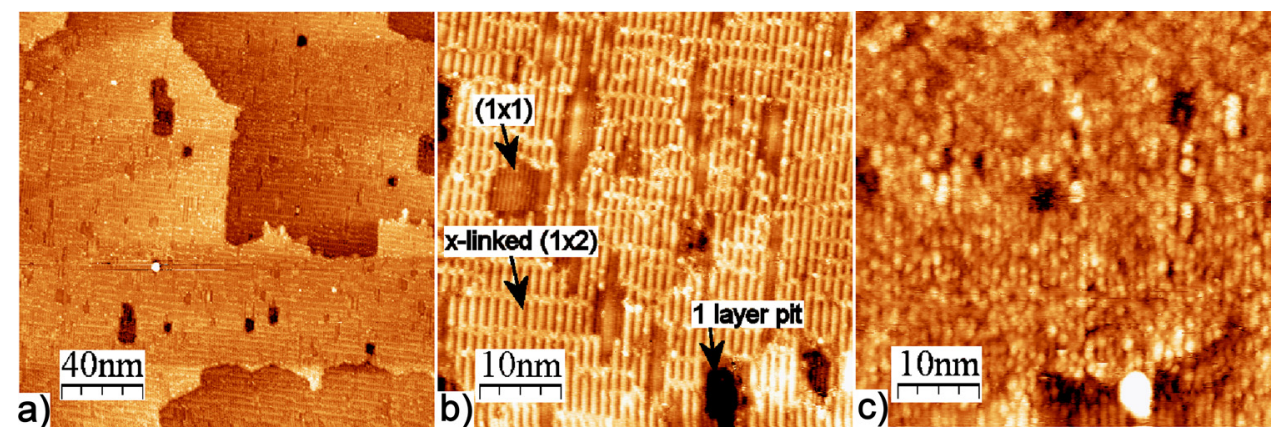

FIG. 1. (Color online) (a) Large area STM image of the clean $\mathrm{TiO}_{2}(110)$ cross-linked $(1 \times 2)$ surface. (b) Close up of the atomic scale structures present on this surface highlighting the near horizontal rows of cross-links and small regions of bulk termination $(1 \times 1)$. (c) The surface saturated with adsorbed molecules following exposure to excess $\mathrm{Cu}^{\mathrm{II}}(\mathrm{hfac})_{2}$. 


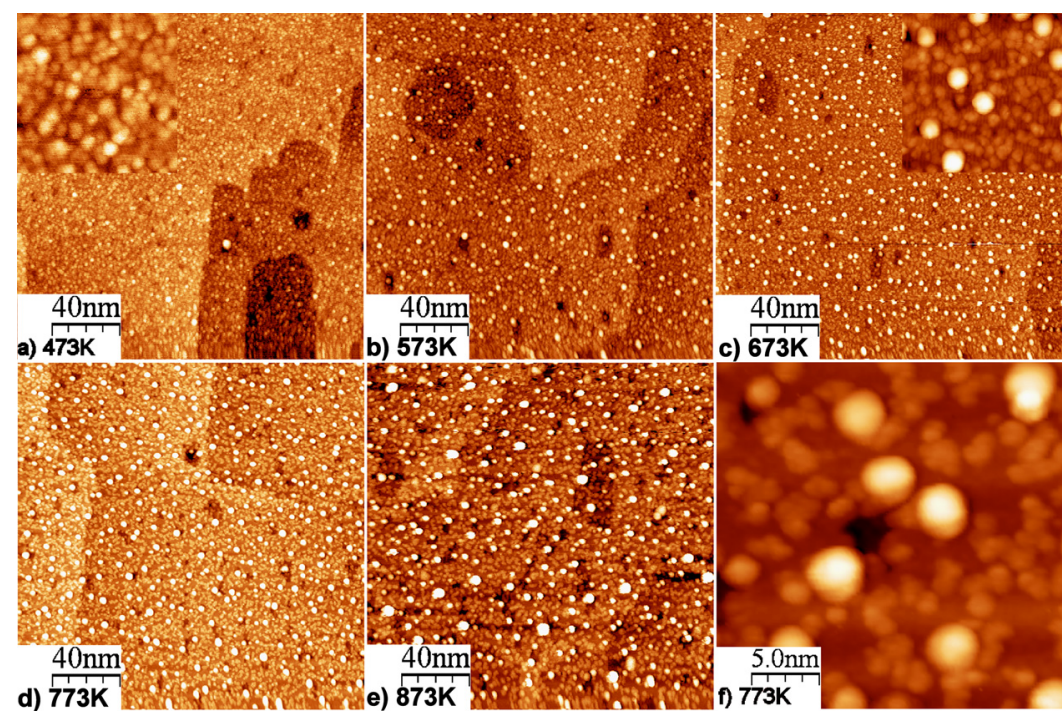

FIG. 2. (Color online) STM images of the saturated surface annealed to (a) $473 \mathrm{~K}$, (b) $573 \mathrm{~K}$, (c) $673 \mathrm{~K}$, (d) $773 \mathrm{~K}$, and (e) $873 \mathrm{~K}$ for 5 min. The inserts in (a) and (c) are $25 \mathrm{~nm}$ square images to contrast the high and uniform particle density in (a) and the development of Cu nanoparticulate islands in (c) surrounded by ligand fragments of much lower height. (f) shows a close up of the film (also $25 \mathrm{~nm}$ square) annealed to $773 \mathrm{~K}$ in which nanoparticles, small pits, and residual fragments are apparent.

behavior was self-limiting as required for an ALD process. There are also no discernible $\mathrm{Cu}$ islands formed from the $\mathrm{RT}$ adsorption, so we expect the $\mathrm{Cu}$ to still be bound to an hfac ligand.

\section{B. Deposition of copper}

Upon annealing the sample to higher and higher temperatures, it is possible to probe the decomposition of the adsorbed complex on the surface and to characterize the spatial arrangement of any deposited material. This capability is essential to understand the wetting or dewetting behavior of the material at the very earliest stages of growth.

In Fig. 2, we show the development of $\mathrm{Cu}$ nanoparticles on the surface and can image the residual ligands that are coadsorbed. In Fig. 2(a), the sample has been annealed at $473 \mathrm{~K}$ and a grainy textured film arises with only a few larger islands visible [one or two of the largest of which are probably due to contaminant clusters as seen in Fig. 1(a)]. The inset shows more clearly the granular film that covers the surface. Further heating to 573 K, Fig. 2(b), sees the clear development of nanoparticles all across the surface with no preferential nucleation at step edges as is found for physical vapor deposited films. ${ }^{16}$ Through $673 \mathrm{~K}$ [Fig. 2(c)], $773 \mathrm{~K}$ [Fig. 2(d)], and $873 \mathrm{~K}$ [Fig. 2(e)], the density of particles begins to fall and the average size increases as the particles ripen. In this wide temperature range, a disordered secondary structure forms between the nanoparticles with a rather uniform apparent height of $\sim 3-4 \AA$ above the terraces [Fig. 2(c) inset and Fig. 2(f)]. The terraces also appear to have acquired significant number of small pit structures which appear more compact than those present on the clean surface. By $873 \mathrm{~K}$, the density of nanoparticles on the surface is dropping rapidly and it appears a small number of relatively large particles are beginning to form.

A statistical analysis of the island size distributions at each of the measured temperatures is shown in Fig. 3. The
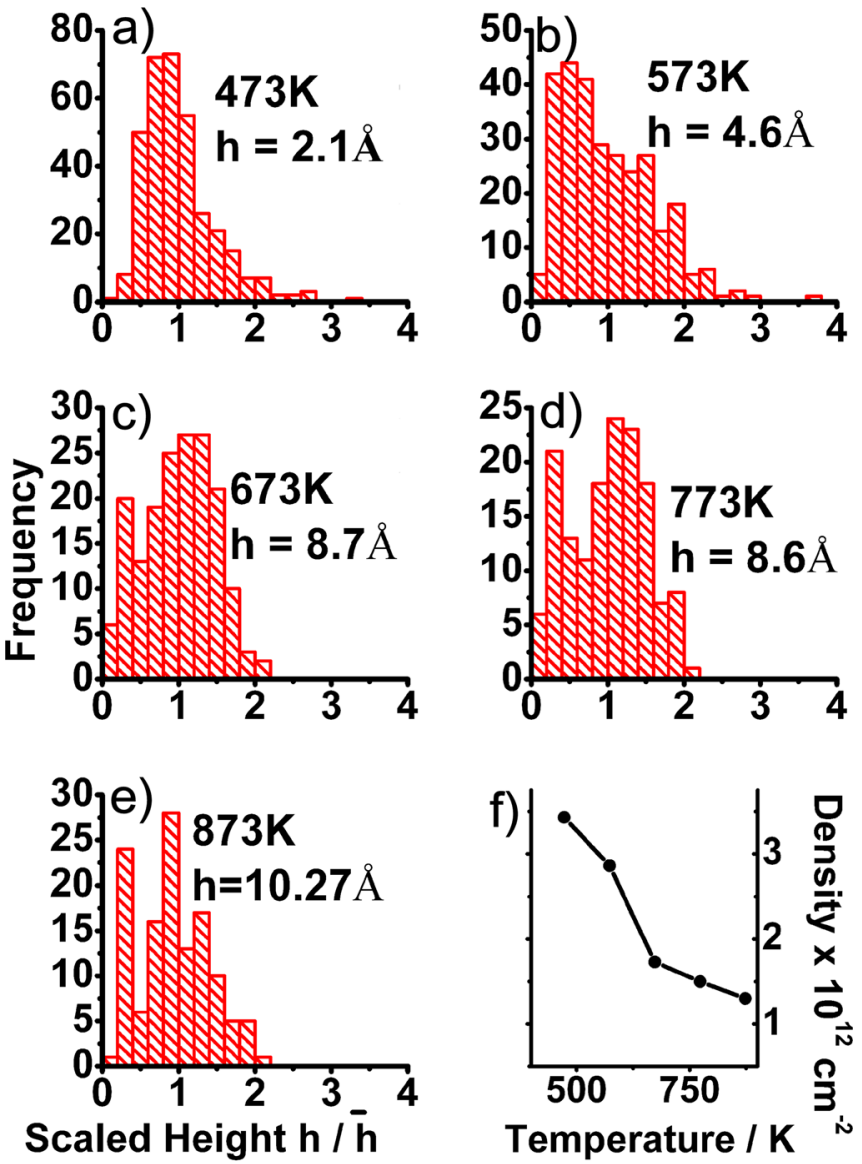

FIG. 3. (Color online) Measured island size and density distributions of the $\mathrm{Cu}$ nanoparticles as a function of annealing temperature. The histograms [(a)-(e)] use the scaled height of the particles for ease of comparison of the distributions in which the actual height (h) is divided by the mean for that distribution ( $\hbar)$. The mean height values for each temperature are given in the histograms. (f) shows the development of the measured surface density of nanoparticles as a function of annealing temperature. 
histograms show the frequency of occurrence of particles as a function of scaled height. Apparent height is the most reliable dimensional measurement on nanoparticles in this size regime as lateral lengthscales are convoluted with the shape of the tip, which has a radius at least comparable to the particle dimension-not least because the tip tends to pick nanoparticles up. Hence, we use apparent height as the dimension to describe the size of the particles. Scaled height, where the apparent height of each particle is divided by mean heights for the distribution, allows us to compare the shapes of particle size distributions. The mean height at each temperature is given on the histograms along with the particle density in the last panel. For all images, we have only included the $\mathrm{Cu}$ nanoparticulate structures in the analysis; on the $473 \mathrm{~K}$ images, the graininess of the film hampers the height measurements of these smallest particles and between 673 and $873 \mathrm{~K}$, the disordered secondary background structure is ignored. The initial distribution is narrow with a significant tail beyond twice the mean size. The mean apparent height at $473 \mathrm{~K}$ is approximately the size one would expect for a $\mathrm{Cu}$ dimer or single molecule on a geometric basis (ignoring electronic structure effects). The mean apparent height is almost constant between 673 and $773 \mathrm{~K}$ which is surprising as the particles are ripening and should be growing in average size. However, a simple explanation is that the particles are simply changing shape and that a change in volume may lead to a slower growth in height in some regimes as the islands spread laterally. The small size of the nanoparticles precludes the imaging of facets. Even the largest islands at $873 \mathrm{~K}$ appear to only contain 6500 atoms, so these are unlikely to show well defined facets as each side of the structure would only have a $\sim 20$ atoms and hence it reasonable to assume a hemispherical shape. ${ }^{2}$

As the particles grow, the distribution between one and two mean radii grows significantly becoming the dominant population at $773 \mathrm{~K}$ and the total width of the distribution narrows to twice the mean radii. A significant number of relatively small particles remain at $873 \mathrm{~K}$ leading to a bimodal distribution. The apparent volume of $\mathrm{Cu}$ derived from the STM images of the particles at $473 \mathrm{~K}$ is $\sim 8 \times 10^{13} \mathrm{Cu}$ atoms $\mathrm{cm}^{-2}$, rising to $\sim 3.4 \times 10^{14} \mathrm{~cm}^{-2}$ at $573 \mathrm{~K}$, where the particle height can be measured better due to visible substrate. At 673 and $773 \mathrm{~K}$, this number is constant at $\sim 5.5 \times 10^{14} \mathrm{~cm}^{-2}$, while it jumps up to $8.3 \times 10^{14} \mathrm{~cm}^{-2}$ after the $873 \mathrm{~K}$ anneal. The overestimation of particle volume is common in STM due to tip shape convolution of the particles lateral extent and the inability to measure voids underneath overhanging edges or a particle-for example, nonwetting spherical particles or those with facets.

\section{Photoemission}

In Fig. 4, we show the XPS results for RT adsorption on the $(1 \times 1)$ terminated surface taken through a sequence of annealing steps which allows us to relate the topography seen in STM to chemical species. Upon adsorption at $298 \mathrm{~K}$, the XPS shows $\mathrm{C} 1 \mathrm{~s}$ spectra in three states as expected corresponding to $285.2 \mathrm{eV} \mathrm{C}-\mathrm{H}, 288.7 \mathrm{eV} \mathrm{C}=\mathrm{O}$, and $292.8 \mathrm{eV}$ $\mathrm{C}^{-\mathrm{F}_{3}}$; $\mathrm{F}$ in two states with $90 \%$ of the signal deriving from the $\mathrm{F}$ in the $688.5 \mathrm{eV} \mathrm{CF}_{3}$ groups and the remainder at higher binding energy $(692 \mathrm{eV})$ assigned to $\mathrm{F}$ bound to the surface; and the presence of $\mathrm{Cu}$ in the +1 oxidation state at $933.0 \mathrm{eV}$. As the annealing temperature increases, the $\mathrm{C} 1 \mathrm{~s}$ spectra changes significantly with a decline of the highest binding energy feature by $573 \mathrm{~K}$ and of the central peak at $773 \mathrm{~K}$. At $873 \mathrm{~K}$, the lowest binding energy feature shifts slightly in energy to $284.5 \mathrm{eV}$. The fluorine $1 \mathrm{~s}$ spectra simply show a gradual decline in the intensity of the main feature with just the residual $\mathrm{F}$ bound to the surface signal remaining at $873 \mathrm{~K}$. The $\mathrm{Cu} 2 \mathrm{p}$ spectra show a single peak with a shift in binding energy and broadening after annealing to $373 \mathrm{~K}$ and then a gradual change to slightly lower binding energy with subsequent annealing.

\section{Discussion}

The deposition of $\mathrm{Cu}^{\mathrm{II}}(\mathrm{hfac})_{2}$ from the vapor phase onto $\mathrm{TiO}_{2}(110)$ at RT is characterized by the chemisorption of the
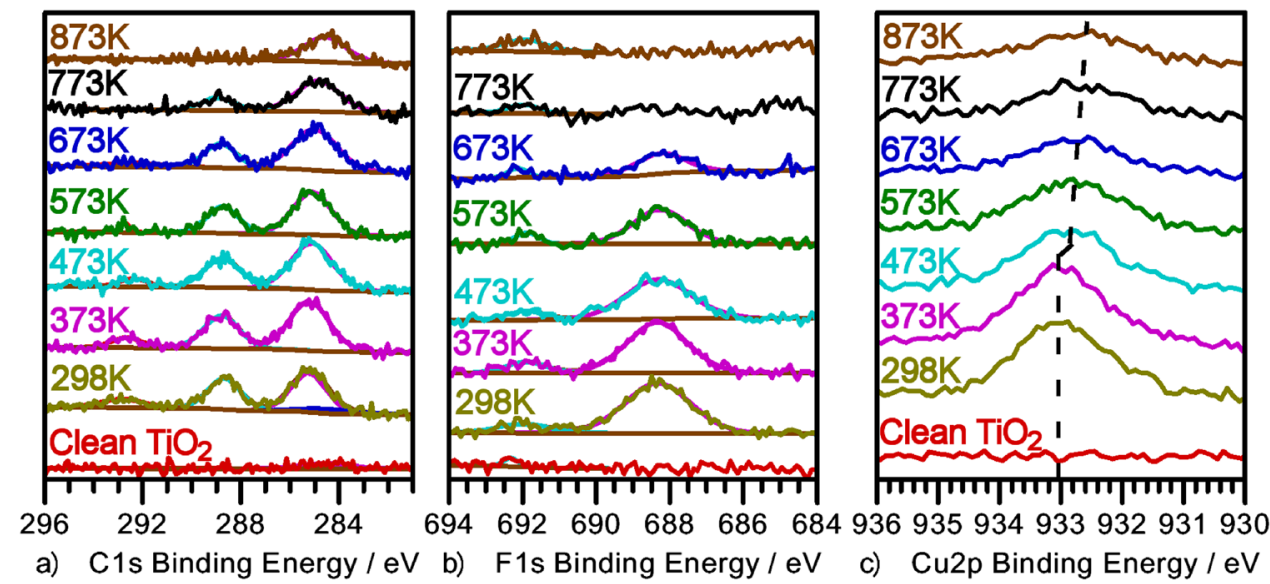

c) Cu2p Binding Energy /

FIG. 4. (Color online) XPS data taken for the $\mathrm{Cu}^{\mathrm{II}}(\mathrm{hfac})_{2}$ adsorbed on a $(1 \times 1)$ terminated surface and annealed for the same temperatures as the $\mathrm{STM}$ images. (a) shows the $\mathrm{C} 1 \mathrm{~s}$ photoemission and three peaks characteristic of the molecule at $285.2 \mathrm{eV} \mathrm{C}-\mathrm{H}, 288.7 \mathrm{eV} \mathrm{C}=\mathrm{O}$, and $292.8 \mathrm{eV} \mathrm{C}-\mathrm{F}_{3}$; (b) shows the $\mathrm{F} 1 \mathrm{~s} \mathrm{spec}-$ tra and two peaks due to the molecules $\mathrm{C}-\mathrm{F}_{3}$ groups and a minor fragment from $\mathrm{F}$ adsorption on the $\mathrm{TiO}_{2}$; (c) shows the $\mathrm{Cu} 2 \mathrm{p}_{3 / 2}$ signal due initially to $\mathrm{Cu}$ below $473 \mathrm{~K}$ and subsequently increasingly due to $\mathrm{Cu}^{0}$ in metallic nanoparticles. 
molecule. The XPS results and STM images indicate the copper is oxidized and that a homogenous layer of the adsorbate forms. After annealing to $373 \mathrm{~K}$, there is little to no change in the spectra, but by $473 \mathrm{~K}$, the $\mathrm{Cu} 2 \mathrm{p}_{3 / 2}$ peak broadens and shifts closer to the value associated with metallic copper. The STM images at this temperature show a grainy textured background and small nanoparticles. We believe the background is due to the adsorbed $\mathrm{Cu}^{\mathrm{I}}$ hfac, hfac ligands, and small $\mathrm{Cu}$ clusters, whereas the nanoparticles are composed of $\mathrm{Cu}$ metal. Further annealing at higher temperatures drives off most of the ligands and the nanoparticles grow in size. The XPS shows a gradual shift toward the metallic state for all $\mathrm{Cu}$ in the spectra and a reduction in intensity as expected for the formation of compact clusters in comparison to a dispersed film. The breadth of the peak arises from the $\mathrm{Cu}$ in two states, as $\mathrm{Cu}^{\mathrm{I}}$ and as $\mathrm{Cu}$ metal, which we cannot resolve with an unmonochromated $\mathrm{x}$-ray source. At $873 \mathrm{~K}$, the $\mathrm{Cu}$ nanoparticles co-exist on the surface with a grainy 3-4 $\AA$ disordered structure. The XPS shows that at this temperature, the only species left on the surface aside from $\mathrm{Cu}$ is a carbon residue, probably in the form of titanium oxy-carbide. ${ }^{17}$ At the higher temperatures, a number of small pits become apparent on the surface which may be due to reaction of adsorbed hydrocarbons to form $\mathrm{H}_{2} \mathrm{O}$ and $\mathrm{CO}$ / $\mathrm{CO}_{2}$.

It is peculiar that $\mathrm{Cu}$ deposited from an adsorbed precursor has no tendency to aggregate at atomic scale step edges on the surface yet $\mathrm{Cu}$ deposited by physical vapor deposition on the $(1 \times 1)$ surface shows a very strong preference for the steps. ${ }^{16}$ However, it should be noted that on a partially reconstructed $(1 \times 2)$ surface, this effect is far less noticeable and a nanoparticle density approaching the defect density on the terraces arises. ${ }^{18}$ It would appear that in the $\mathrm{Cu}^{\mathrm{I}}$ hfac cross linked $\mathrm{TiO}_{2}$ precursor-substrate system, where the cross-links of the $(1 \times 2)$ reconstruction can nucleate island growth, ${ }^{12}$ that the $\mathrm{Cu}$ islands do not prefer to nucleate on these sites or the step edges. Instead a very uniform array of small particles forms initially because the adsorption site for the molecules determines the structure. It is the slow release of $\mathrm{Cu}$ to form small $\mathrm{Cu}$ clusters co-adsorbed with the ligands which then ripen into a bimodal distribution. The origin of the bimodal size distribution probably arises due to the surface heterogeneity induced by the crosslinks of the reconstruction which can the pin $\mathrm{Cu}$ particles and reduce mobility. As the particle distribution ripens at elevated temperature mobile unpinned $\mathrm{Cu}$ (adsorbed between the crosslinks) will aggregate onto pinned clusters at the crosslinks. At a characteristic size for the given temperature larger islands could depin and become more mobile rapidly mopping up neighboring material leading to large islands. The larger structures would show a greatly reduced mobility and appear sitting in a denuded region while most of the surface is still covered with smaller pinned clusters. Indeed the larger particles appear to be well separated in the images [Figs. 2(c)-2(e)]. The influence of the ligand fragments may also play a role in pinning clusters or reducing adatom and cluster mobility which may offer a method to induce homogeneous nucleation and growth in ALD if this effect could be controlled.

\section{SUMMARY AND CONCLUSIONS}

We have studied the adsorption of $\mathrm{Cu}^{\mathrm{II}}(\mathrm{hfac})_{2}$ on the surface of a model oxide system, $\mathrm{TiO}_{2}(110)$, and probed the molecular stability with respect to thermal cycling. We find that at $473 \mathrm{~K}$ the adsorbed molecules begin to dissociate and release $\mathrm{Cu}$ atoms which aggregate and form $\mathrm{Cu}$ nanoparticles. These $\mathrm{Cu}$ nanoparticles ripen over time and the size (height) distribution develops into a bimodal distribution. Unlike some other organometallic systems, which show a bimodal distribution due to enhanced nucleation at surface step edges ${ }^{19}$ the nanoparticles do not preferentially form at steps.

\section{ACKNOWLEDGMENT}

The authors thank Simon Elliott of the Tyndall National Institute, Ireland for very helpful discussions.

${ }^{1}$ B. S. Lim, A. Rahtu, and R. G. Gordon, Nature Mater. 2, 749 (2003).

${ }^{2}$ U. Diebold, J.-M. Pan, and T. E. Madey, Phys. Rev. B 47, 3868 (1993).

${ }^{3}$ B. H. Lee, J. K. Hwang, J. W. Nam, S. U. Lee, J. T. Kim, S.-M. Koo, A. Baunemann, R. A. Fischer, and M. M. Sung, Angew. Chem., Int. Ed 48, 4536 (2009).

${ }^{4}$ T. J. Knisley, T. C. Ariyasena, T. Sajavaara, M. J. Saly, and C. H. Winter, Chem. Mater. 23, 4417 (2011).

${ }^{5}$ R. Solanki and B. Pathangey, Electrochem. Solid-State Lett. 3, 479 (2000).

${ }^{6}$ J. S. Mulley, R. A. Bennett, and V. R. Dhanak, Surf. Sci. 602, 2967 (2008).

${ }^{7}$ R. A. Bennett, P. Stone, N. J. Price, and M. Bowker, Phys. Rev. Lett. 82, 3831 (1999).

${ }^{8}$ P. A. Mulheran, M. Nolan, C. S. Browne, M. Basham, E. Sanville, and R. A. Bennett, Phys. Chem. Chem. Phys. 12, 9763 (2010).

${ }^{9}$ M. Bowker and R. A. Bennett, J. Phys. Condens. Matter. 21, 474224 (2009).

${ }^{10}$ M. Bowker and R. A. Bennett, J. Phys. Condens. Matter 22, 059801 (2010).

${ }^{11}$ R. D. Smith, R. A. Bennett, and M. Bowker, Phys. Rev. B 66, 035409 (2004).

${ }^{12}$ R. A. Bennett, D. M. Tarr, and P. A. Mulheran, J. Phys. Condens. Matter 15, S3139 (2003).

${ }^{13}$ M. Bowker, S. Poulston, R. A. Bennett, P. Stone, A. H. Jones, S. Haq, and P. Hollins, J. Mol. Catal. A: Chem 131, 185 (1998).

${ }^{14}$ I. Horcas, R. Fernandez, J. M. Gomez-Rodriguez, J. Colchero, J. Gomez-Herrero, and A. M. Baro, Rev. Sci. Instrum. 78, 013705 (2007).

${ }^{15}$ G. M. Nuesca and J. A. Kelber, Thin Solid Films 262, 224 (1995).

${ }^{16}$ D. A. Chen, M. C. Bartelt, R. Q. Hwang, and K. F. McCarty, Surf. Sci. 450, 78 (2000).

${ }^{17}$ E. Benko, T. L. Barr, S. Hardcastle, E. Hoppe, A. Bernasik, and J. Morgiel, Ceram. Int. 27, 637 (2001).

${ }^{18}$ J. Zhou and D. A. Chen, Surf. Sci. 527, 183 (2003).

${ }^{19}$ R. A. Bennett, M. A. Newton, R. D. Smith, M. Bowker, and J. Evans, Surf. Sci. 487, 223 (2001). 